Egyptian Journal of Occupational Medicine, 2020; 43 (3) : 709 - 726

\title{
THE IMPACT OF AN EDUCATIONAL TRAINING PROGRAM ON NURSES IN REDUCTION OF
} VENTILATOR ASSOCIATED PNEUMONIA

\author{
By \\ Khalifa EM ${ }^{1}$ and Seif Eldin $\mathrm{AS}^{1,2}$ \\ ${ }^{1}$ Department of Occupational and Environmental Medicine, Faculty of Medicine, Cairo University, Egypt, \\ ${ }^{2}$ Department of Health Sciences, Faculty of Health Sciences and Rehabilitation, Princess Nourah bint \\ Abdulrahman University, Riyadh, Saudia Arabia. \\ Corresponding author: Khalifa EM: eman.khalifa@kasralainy.edu.eg
}

\begin{abstract}
Introduction: Ventilator Associated Pneumonia (VAP) is a critical hospital acquired infection causing high morbidity and mortality among critically ill patients in intensive care units (ICU). Nurses play a fundamental role in prevention of VAP by adherence to evidence-based guidelines. Lack of knowledge and inadequate infection control program application are barriers against reduction of VAP incidence. Aim of work: To evaluate the effectiveness of an educational and training program of ICU nurses on their knowledge and practices regarding evidenced based guidelines for VAP prevention, to detect its impact on the incidence rate of VAP and to raise the nurses' awareness of their occupational health and safety by adherence to infection control guidelines. Materials and methods: A quasi- experimental pre-post design, interventional study was conducted on seventy nurses at five ICUs at the Manial hospital, Cairo University. Pre- intervention questionnaire and observational checklist were used to assess nurses' knowledge and practice of care bundle for VAP prevention. An educational and training programs about occupational health, safety and infection control measures was applied, and then post- intervention assessment was followed. Analysis of VAP incidence rate was performed after reviewing the medical records. Results: There was statistically significant improvement of knowledge in the post-intervention assessment except for the use of chlorhexidine which showed non-statistically significant differences between pre and post intervention $(>0.05)$. Nurses' practices regarding infection
\end{abstract}


control measures and care bundle for VAP prevention showed statistically significant improvement in the post- intervention assessment $(<0.05)$ except for the use of clean unsterilized gloves and use of chlorhexidine swab which were the least practices adopted in $4.3 \%$ and $12.9 \%$ of nurses respectively. The mean VAP incidence rate was $24.86 \pm 5.19$ and was reduced to $5.47 .96 \pm$ in the post intervention phase (statistically significant). Conclusion: There was an overall improvement of nurses' knowledge and practices of evidence based guidelines for VAP prevention associated with reduction of VAP incidence rate after the implementation of the program.

Keywords: Ventilator-associated pneumonia (VAP), Intensive Care Unit, Evidence based guidelines, Occupational health and safety, Nurses and Incidence rate.

\section{Introduction}

Ventilator associated pneumonia (VAP) is a hospital acquired new developing pneumonia which is very common in intensive care units (ICU). It ranked the second most common nosocomial infection and it is responsible for high morbidity and mortality among critically ill patients in ICU (Barbier et al., 2013; Ferreira et al., 2016). It is the fastest device associated hospital infection and its incidence is $22.8 \%$ among patient on mechanical ventilator (Rosenthal et al., 2006).

The modifiable risk factors of VAP are related to the hospital environment as patient treatment and nurse's practices and interventions (CDC, 2016). Critical care nurses play a vital role in prevention of VAP though prevention of modifiable risk factors and detection of early symptoms (Myrianthefs et al., 2004).
A study was done by Seliman et al (2011) found that the routine nursing practice of mechanically ventilated patients regarding endotracheal tube (ETT) suctioning and enteral feeding was unsatisfactory and it was a risk of aspiration.

A care bundle is a group of multidisciplinary interventions which are evidenced-based and applied to mechanically ventilated patient to prevent and reduce VAP rate, length of hospital stay and hospital costs (Hellyer et al., 2016).

Nurses at ICU provide medical care through group of maneuvers and interventions during their routine non drug based nursing care and they have a fundamental role in prevention of VAP by adherence to evidence-based guidelines (Esteban et al., 2013).

Lack of knowledge among nurses 
of such guidelines, lack of an adequate infection control program application regarding hand wash, use of personal protective equipment and deficient training leads to spread of VAP (Osti et al., 2017).

Both of the patient safety and healthcare provider safety are targeted. Nurses should protect patients as well as themselves by following infection control guidelines and standard precautions such as hand hygiene, use of personal protective equipment, environmental hygiene and safe use and disposal of sharp instruments. Safe practices should be adopted while providing care to the patient with invasive devices such as an endotracheal tube, tracheostomy tube and nasogastric tube (Augustyn, 2007).

\section{Aim of work}

The aim of this study is to evaluate the effectiveness of an educational and training program of ICU nurses on their knowledge and practices regarding evidenced based guidelines for VAP prevention, to detect its impact on the incidence rate of VAP and to raise the nurses' awareness of their occupational health and safety by adherence to infection control guidelines and standard precautions.

\section{Materials and methods}

- Study Design: A quasi- experimental pre-post design, interventional study.

- Place and duration of the study: the study was conducted in five intensive care units at the Manial hospital, Cairo University from January to June 2017.

- Study sample: The participants included a sample of all available nurses (70 nurses) who were providing care to mechanically ventilated patients and were working in the five medical and surgical ICUs of the Manial hospital, Cairo University. They were included in the study regardless of their age, gender, years of experience, job rank and education. The ages of the studied ICU nurses ranged from 22- 48 years with a mean of $32.9 \pm 8$. Years of experience ranged from 6 months- 28 years with mean of $12.6 \pm 8.7$. Female represented $(76 \%)$ and the vast majority was married $(81.5 \%)$, regular nurses represented (90\%) of the studied group. Most of them were educated at nursing institute (57\%), few (3\%) had a bachelor degree of nursing. The majority worked in shift work (83\%) and the mean working hours per week was $37.5 \pm 3.7$.

Study methods: All participants were subjected to the following: 
I- Predesigned interview questionnaire developed by the researchers into Arabic language after reviewing the relevant literature of (Abusaad and Tantawey, 2010; Lin et al, 2014 and CDC, 2016).

The questionnaire was reviewed and tested for its content validity before application by two expert reviewers from infection control committee at Cairo University hospitals. Seven nurses were excluded from the study after participation in testing the questionnaire for the first time (Pilot study). The questionnaire was modified after conducting this pilot study, with exclusion of indistinct and incomprehensible questions. The interview questionnaire consisted of:

\section{A- Sociodemographic history of} nurses (age, gender, marital status and education) and occupational history (years of experience, job rank and working hours per week, working schedule, additional job and previous job) also the history of any previous training taken.

B- Sixteen questions were used to assess nurses' knowledge about VAP (pre intervention assessment), four questions were used for assessment of general knowledge about VAP and it included (the definition, diagnostic criteria, causative organisms and risk factors). Twelve questions were used to assess knowledge about nurses interventions and infection control measures for prevention of VAP, it included 4 questions about hand hygiene, 2 questions about personal protective equipment (PPE), 1 question about frequency of endotracheal tube suctioning (ETT), 1 question about suctioning the subglottic region, 2 questions about oral care, 1 question about measuring endotracheal tube (ET) cuff pressure and 1 question about patient position. Scoring system was developed with score (0) for incorrect answer and score (1) for the correct answer. The questionnaire took 20 minutes to be answered.

\section{C- The observational checklist was} used to assess and evaluate the nurses' practice and performance for VAP prevention based on the evidence based guidelines and this was selected from CDC guidelines (WHO, 2009 and CDC, 2012) .

This observational checklist was given a score of 18 which was used to assess the nurses' practice of 7 techniques during suctioning of 
endotracheal tube (ETT) secretions, 2 steps during care of subglottic region, 1 for assessment of dealing with ET cuff and maintaining its pressure between 20-30 $\mathrm{cm} \mathrm{H}_{2} \mathrm{O}, 2$ for controlling gastric reflux and 3 observations during oral care. Observation of care of mechanical ventilator equipment took 3 score. The correct practice took score (1) and the incorrect one took (0) score. Each observation was done to every nurse individually from the start of the procedure till its end and it took about 15 minutes.

All pre intervention assessment took one month to be performed.

\section{II-Educational and training program}

The program started after performing the pre assessment of deficit and shortage in nurses' knowledge and practices about VAP.

The occupational education and training program consisted of theoretical and practical parts about the following:

1- Infection control guidelines and standard precautions as appropriate hand wash, using personal protective equipment, aseptic techniques, environmental cleaning, waste management, and sterilization.

2- Technique of oral care for mechanically ventilated patients was carried out by using soft toothbrush with the application of antiseptic agents.

3- Suction technique from the subglottic area and from the endotracheal tube.

4- Bed positioning, enteral feeding, cuff pressure monitoring and optimum use of mechanical ventilator device.

The theoretical part was performed in a hall at Cairo University hospital after subdivision of the whole nurses into two groups. Each group took 3 lectures with total of 6 lectures. Different teaching methods were used, face to face discussion, power point presentation, videos, posters and handouts. Practical training was given at each individual ICU after subdivision into a total of 6 small groups. Each group took 2 sessions with total of 12 sessions and they were trained on how to apply safe practical procedures for both of patients and themselves to maintain their occupational safety.

The nurses trained on mechanically ventilated patient in ICU. The application of the program took 2 months.

Post intervention assessment of nurses〉 knowledge and practices 
was performed after 2 months of implementation of the program using the same pre intervention questionnaire and took 1 month.

\section{- Analysis of VAP incidence rate}

The VAP rate (episode) per 1000 ventilator days is calculated by dividing the

number of VAP cases by the number of ventilator days and multiplying by 1000. The medical records of the five ICUs were reviewed for two month pre-intervention and two month postintervention for comparison. The collected data was the total number of patients on mechanical ventilator, the number of patients on mechanical ventilator who had developed VAP, the number of ventilator days.

\section{Consent}

Verbal consent was taken from all nurses who participated in the study and confidentiality was maintained.

\section{Ethical approval}

The study procedures were approved by Ethical Review Committee of the

Occupational and Environmental Medicine Department, Faculty of Medicine, Cairo University.

\section{Data management}

Data were coded and entered using the statistical package SPSS (Statistical Package for the Social Sciences) version 25. Data was summarized using mean, standard deviation, median, minimum and maximum in quantitative data and using frequency (count) and relative frequency (percentage) for categorical data. Comparisons between quantitative variables were done using paired t test and Wilcoxon Rank test for not normally distributed data. For comparing categorical data, Chi square $(\chi 2)$ test was performed. P-values less than 0.05 were considered as statistically significant (Chan, 2003). 


\section{Results}

Table (1): Frequency distribution of nurses' general knowledge about VAP at pre and post interventional assessment.

\begin{tabular}{|c|c|c|c|c|c|c|}
\hline \multirow{2}{*}{$\begin{array}{l}\text { Nurses' general } \\
\text { knowledge about VAP }\end{array}$} & \multicolumn{2}{|c|}{$\begin{array}{c}\text { Pre intervention test } \\
\text { No: } 70\end{array}$} & \multicolumn{2}{|c|}{$\begin{array}{l}\text { Post intervention test } \\
\text { No: } 70\end{array}$} & \multirow{2}{*}{$\chi^{2}$} & \multirow{2}{*}{ p-value } \\
\hline & $\begin{array}{c}\text { Incorrect } \\
\text { No }(\%)\end{array}$ & $\begin{array}{l}\text { Correct } \\
\text { No }(\%)\end{array}$ & $\begin{array}{c}\text { Incorrect } \\
\text { No }(\%)\end{array}$ & $\begin{array}{l}\text { Correct } \\
\text { No }(\%)\end{array}$ & & \\
\hline 1) Definition of VAP & $24(34.3 \%)$ & $46(65.7 \%)$ & $3(4.3 \%)$ & $95.7 \%) 67$ & 20.236 & $<0.001 * *$ \\
\hline 2) Diagnostic criteria & $68.6 \%)) 48$ & $31.4 \%)) 22$ & $9(12.9 \%)$ & $87.1 \%) 61$ & 45.010 & $<0.001 * *$ \\
\hline $\begin{array}{l}\text { 3) Causative } \\
\text { organisms }\end{array}$ & $34.3 \%)) 24$ & $65.7 \%)) 46$ & $14.3 \%)) 10$ & $85.7 \%) 60$ & 7.614 & $0.006 * *$ \\
\hline 4) Risk factors & $35.7 \%)) 25$ & $64.3 \%)) 45$ & $5.7 \%)) 4$ & $94.3 \%) 66$ & 19.180 & $<0.001 * *$ \\
\hline
\end{tabular}

** Highly statistically significant difference.

VAP: Ventilator Associated Pneumonia

Table (1) showed that there was a highly statistically significant improvement of general knowledge answers in the post intervention assessment $(p<0.05)$. The highest score for incorrect answers in the pre intervention assessment was for the diagnostic criteria of VAP $(68.6 \%)$. 


\section{Table (2): Frequency distribution of nurses' knowledge about evidence -based guidelines for prevention of VAP at pre and post interventional assessment.}

\begin{tabular}{|c|c|c|c|c|c|c|}
\hline \multirow{2}{*}{$\begin{array}{l}\text { Nurses' knowledge about evidence } \\
\text {-based guidelines for VAP } \\
\text { prevention }\end{array}$} & \multicolumn{2}{|c|}{ Pre intervention test } & \multicolumn{2}{|c|}{ Post intervention test } & \multirow{2}{*}{$\chi^{2}$} & \multirow{2}{*}{ p-value } \\
\hline & $\begin{array}{c}\text { Incorrect } \\
\text { No }(\%)\end{array}$ & $\begin{array}{l}\text { Correct } \\
\text { No }(\%)\end{array}$ & $\begin{array}{c}\text { Incorrect } \\
\text { No }(\%)\end{array}$ & $\begin{array}{l}\text { Correct } \\
\text { No }(\%)\end{array}$ & & \\
\hline $\begin{array}{l}\text { (Hand hygiene during ETT } \\
\text { suctioning \& oral care) } \\
\text { 1) When do you perform routine } \\
\text { hand washing? } \\
\text { 2) What was the frequency of hand } \\
\text { washing? } \\
\text { 3) When do you perform a septic } \\
\text { hand washing? } \\
\text { 4) What was the proper contact time } \\
\text { of alcohol rub? }\end{array}$ & $\begin{array}{l}30(42.9 \%) \\
43(61.4 \%) \\
26(37.1 \%) \\
48(68.6 \%)\end{array}$ & $\begin{array}{l}40(57.1 \%) \\
27(38.6 \%) \\
44(62.9 \%) \\
22(31.4 \%)\end{array}$ & $\begin{array}{c}5(7.1 \%) \\
13(18.6 \%) \\
4(5.7 \%) \\
7(10 \%)\end{array}$ & $\begin{array}{l}65(92.9 \%) \\
57(81.4 \%) \\
66(94.3 \%) \\
63(90 \%)\end{array}$ & $\begin{array}{l}23.810 \\
26.786 \\
20.533 \\
50.340\end{array}$ & $\begin{array}{l}<0.001 * * \\
<0.001 * * \\
<0.001 * * \\
<0.001 * *\end{array}$ \\
\hline $\begin{array}{l}\text { (Use of personal protective } \\
\text { equipment) } \\
\text { 1) Did you wear pair of gloves } \\
\text { during suctioning\& oral care? } \\
\text { 2) What are the types PPE used? }\end{array}$ & $\begin{array}{l}15(21.4 \%) \\
50(71.4 \%)\end{array}$ & $\begin{array}{l}55(78.6 \%) \\
20(28.6 \%)\end{array}$ & $\begin{array}{l}5(7.1 \%) \\
9(12.9 \%)\end{array}$ & $\begin{array}{l}65(92.9 \%) \\
61(87.1 \%)\end{array}$ & $\begin{array}{l}5.833 \\
49.245\end{array}$ & $\begin{array}{l}<0.016 * \\
<0.001 * *\end{array}$ \\
\hline $\begin{array}{l}\text { Suctioning } \\
\text { 1) What was the frequency of } \\
\text { suctioning of ETT? } \\
\text { 2) What was the frequency of } \\
\text { suctioning of subglottic region? }\end{array}$ & $\begin{array}{l}28(40 \%) \\
18(25.7 \%)\end{array}$ & $\begin{array}{l}42(60 \%) \\
52(74.3 \%)\end{array}$ & $\begin{array}{l}7(10 \%) \\
2(2.9 \%)\end{array}$ & $\begin{array}{l}63(90 \%) \\
68(97.1 \%)\end{array}$ & $\begin{array}{l}16.800 \\
14.933\end{array}$ & $\begin{array}{l}<0.001 * * \\
<0.001 * *\end{array}$ \\
\hline $\begin{array}{l}\text { Oral care } \\
\text { Did you do oral care every } 8 \text { hours? }\end{array}$ & $50(71.4 \%)$ & $20(28.6 \%)$ & $19(27.1 \%)$ & $51(72.9 \%)$ & 27.463 & $<0.001 * *$ \\
\hline $\begin{array}{l}\text { Did you measure endotracheal } \\
\text { tube cuff pressure? }\end{array}$ & $36(51.4 \%)$ & $34(48.6 \%)$ & $8(11.4 \%)$ & $62(88.6 \%)$ & 25.985 & $<0.001 * *$ \\
\hline $\begin{array}{l}\text { Did you elevate the head of bed } \\
\text { 30-45? }\end{array}$ & $15(21.4 \%)$ & $55(78.6 \%)$ & $1(1.4 \%)$ & $69(98.6 \%)$ & 13.831 & $<0.001 * *$ \\
\hline
\end{tabular}

*: Statistically significant difference,

ETT: Endotracheal tube
**: Highly statistically significant difference. PPE: Personal protective equipment 
Table (2) illustrated a list of questions used to assess nurses' knowledge about evidence -based guidelines for prevention of VAP. There was a statistically significant improvement of knowledge answers in the post intervention assessment in most of questions $(p<0.05)$ except for knowledge about the use of chlorhexidine antiseptic which showed non-statistically significant differences between pre and post intervention( $p>0.05)$ (data was not tabulated).

\section{Table (3): Frequency distribution of nurses' practices about infection control measures during invasive procedures at pre and post interventional assessment.}

\begin{tabular}{|c|c|c|c|c|c|c|}
\hline \multirow{2}{*}{$\begin{array}{l}\text { Nurses' practices } \\
\text { about infection control } \\
\text { measures during invasive } \\
\text { procedures }\end{array}$} & \multicolumn{2}{|c|}{ Pre intervention test } & \multicolumn{2}{|c|}{ Post intervention test } & \multirow[b]{2}{*}{$\chi^{2}$} & \multirow{2}{*}{ p-value } \\
\hline & \begin{tabular}{|l|} 
Not done \\
No (\%)
\end{tabular} & $\begin{array}{c}\text { Done } \\
\text { No (\%) }\end{array}$ & $\begin{array}{c}\text { Not done } \\
\text { No (\%) }\end{array}$ & $\begin{array}{c}\text { Done } \\
\text { No (\%) }\end{array}$ & & \\
\hline $\begin{array}{l}\text { 1) Aseptic hand wash before } \\
\text { invasive procedures } \\
\text { 2) Aseptic hand wash after } \\
\text { invasive procedures } \\
\text { 3) Use of clean unsterilized } \\
\text { gloves } \\
\text { 4) Wear aprons } \\
\text { 5) Wear masks }\end{array}$ & $\mid \begin{array}{c}18(25.7 \%) \\
55(78.6 \%) \\
11(15.7 \%) \\
63(90 \%) \\
43(61.4 \%)\end{array}$ & $\begin{array}{l}52(74.3 \%) \\
15(21.4 \%) \\
59(84.3 \%) \\
7(10 \%) \\
27(38.6 \%)\end{array}$ & $\begin{array}{c}0(0 \%) \\
16(22.9 \%) \\
4(5.7 \%) \\
41(58.6 \%) \\
13(18.6 \%)\end{array}$ & $\begin{array}{l}70(100 \%) \\
54(77.1 \%) \\
66(94.3 \%) \\
29(41.4 \%) \\
57(81.4 \%)\end{array}$ & \begin{tabular}{|c|}
20.656 \\
\\
43.466 \\
\\
3.659 \\
18.098 \\
26.786
\end{tabular} & $\begin{array}{r}<0.001 * * * \\
<0.001 * * \\
0.09 \\
<0.001 * * \\
<0.001 * *\end{array}$ \\
\hline
\end{tabular}

** Highly statistically significant difference.

Table (3) illustrated nurses' practices observed regarding application of infection control measures and it showed that most defective practices was wearing of aprons in $90 \%$ of nurses followed by non-commitment to aseptic hand washing after invasive procedures in $78.6 \%$. There was a statistically significant differences and improvement of practices in the post intervention assessment $(\mathrm{p}<0.05)$ except for the use of clean unsterilized gloves which showed non-statistically significant differences $(p>0.05)$. 
Table (4): Frequency distribution of nurses' practices about a care bundle for VAP at pre and post interventional assessment.

\begin{tabular}{|c|c|c|c|c|c|c|}
\hline \multirow[b]{2}{*}{ Nurses' practices } & \multicolumn{2}{|c|}{ Pre intervention test } & \multicolumn{2}{|c|}{ Post intervention test } & \multirow[b]{2}{*}{$\chi^{2}$} & \multirow[b]{2}{*}{ P-value } \\
\hline & $\begin{array}{l}\text { Not done } \\
\text { No }(\%)\end{array}$ & $\begin{array}{c}\text { Done } \\
\text { No }(\%)\end{array}$ & $\begin{array}{c}\text { Not done } \\
\text { No }(\%)\end{array}$ & $\begin{array}{c}\text { Done } \\
\text { No }(\%)\end{array}$ & & \\
\hline $\begin{array}{l}\text { A) Suctioning of ETT } \\
\text { secretion } \\
\text { 1) Using a sterile catheter } \\
\text { 2) Frequent suctioning }\end{array}$ & $\begin{array}{l}16(22.9 \%) \\
38(54.3 \%)\end{array}$ & $\begin{array}{l}54(77.1 \%) \\
32(45.7 \%)\end{array}$ & $\begin{array}{l}5(7.1 \%) \\
14(20 \%)\end{array}$ & $\begin{array}{c}65(92.9 \%) \\
56(80 \%)\end{array}$ & $\begin{array}{r}6.779 \\
17.622\end{array}$ & $\begin{array}{r}0.009 * * \\
<0.001 * *\end{array}$ \\
\hline $\begin{array}{l}\text { B) Care of subglottic } \\
\text { region } \\
\text { 1) Clear subglottic } \\
\text { secretion } \\
\text { 2) Use ETT with extra } \\
\text { lumen }\end{array}$ & $\begin{array}{l}22(31.4 \%) \\
40(57.1 \%)\end{array}$ & $\begin{array}{l}48(68.6 \%) \\
30(42.9 \%)\end{array}$ & $\begin{array}{c}1(1.4 \%) \\
17(24.3 \%)\end{array}$ & $\begin{array}{l}69(98.6 \%) \\
53(75.7 \%)\end{array}$ & $\begin{array}{l}22.943 \\
15.654\end{array}$ & $\begin{array}{l}<0.001 * * \\
<0.001 * *\end{array}$ \\
\hline $\begin{array}{l}\text { C) Maintain ETT cuff } \\
\text { pressure between } 20-30 \\
\mathrm{cmH}_{2} \mathrm{O}\end{array}$ & $44(62.9 \%)$ & $26(37.1 \%)$ & $12(17.1 \%)$ & $58(82.9 \%)$ & 30.476 & $<0.001 * *$ \\
\hline $\begin{array}{l}\text { D) Control of gastric } \\
\text { reflux } \\
\text { 1) Semi recumbent } \\
\text { positioning of bed at } 30 \text { - } \\
\text { 45degree } \\
\text { 2) Monitoring gastric } \\
\text { residual volume }\end{array}$ & $\begin{array}{l}17(24.3 \%) \\
40(57.1 \%)\end{array}$ & $\begin{array}{l}53(75.7 \%) \\
30(42.9 \%)\end{array}$ & $\begin{array}{c}3(4.3 \%) \\
12(17.1 \%)\end{array}$ & $\begin{array}{l}67(95.7 \%) \\
58(82.9 \%)\end{array}$ & $\begin{array}{l}11.433 \\
23.986\end{array}$ & $\begin{array}{r}0.001 * * \\
<0.001 * *\end{array}$ \\
\hline $\begin{array}{l}\text { E) Oral care } \\
\text { Brushing of teeth and gums }\end{array}$ & $47(67.1 \%)$ & $23(32.9 \%)$ & $25(35.7 \%)$ & $45(64.3 \%)$ & 13.840 & $<0.001 * *$ \\
\hline $\begin{array}{l}\text { F) Mechanical ventilator } \\
\text { equipment care } \\
\text { 1) Avoid unnecessary } \\
\text { circuit changes } \\
\text { 2) Maintain closed circuit } \\
\text { system } \\
\text { 3) Avoid unnecessary } \\
\text { change of filter }\end{array}$ & $\begin{array}{l}28(40 \%) \\
34(48.6 \%) \\
15(21.4 \%)\end{array}$ & $\begin{array}{l}42(60 \%) \\
36(51.4 \%) \\
55(78.6 \%)\end{array}$ & $\begin{array}{c}6(8.6 \%) \\
9(12.9 \%) \\
4(5.7 \%)\end{array}$ & $\begin{array}{l}64(91.4 \%) \\
61(87.1 \%) \\
66(94.3 \%)\end{array}$ & $\begin{array}{c}18.801 \\
20.978 \\
7.368\end{array}$ & $\begin{array}{r}<0.001 * * \\
<0.001 * * \\
\mathbf{0 . 0 1 2} *\end{array}$ \\
\hline
\end{tabular}

*: Statistically significant difference

** : Highly statistically significant difference.

ETT: Endotracheal tube 
Table (4) illustrated nurses' practices monitored through the observational checklist regarding adherence to a care bundle for VAP. It showed that the most deficient practices were brushing of teeth, maintaining low cuff pressure between $20-30 \mathrm{cmH} 2 \mathrm{O}$ in $67.1 \%, 62.9 \%$ of nurses respectively, followed by $57.1 \%$ for both of the use of endotracheal tube with extra lumen and monitoring gastric volume.

There were statistically significant differences and improvement of practices in the post intervention assessment $(<0.05)$ except for the use of clean unsterilized gloves and use of chlorhexidine swab which were the least practices not performed in $4.3 \%$ and $12.9 \%$ of nurses respectively and they showed non-statistically significant differences $(\mathrm{p}>0.05)$ (data was not tabulated).

Table (5): Incidence rate of VAP among mechanically ventilated patients in pre and post intervention phase of the study.

\begin{tabular}{|c|c|c|c|c|}
\hline Tota & $\begin{array}{l}\text { Two months pre } \\
\text { intervention }\end{array}$ & $\begin{array}{l}\text { Two months post } \\
\text { intervention }\end{array}$ & $Z$ score & p value \\
\hline rate in all icos & $\begin{array}{c}\text { (22.4/1000 ventilator } \\
\text { days })\end{array}$ & (9/1000 ventilator day) & \multirow[b]{2}{*}{-2.023} & \multirow[b]{2}{*}{$0.043 *$} \\
\hline $\begin{array}{l}\text { Mean } \pm \text { SD of VAP } \\
\text { Minimum-maximum }\end{array}$ & $\begin{array}{c}24.86 \pm 5.19 \\
16.6-30.3\end{array}$ & $\begin{array}{c}5.47 .96 \pm \\
0-17\end{array}$ & & \\
\hline
\end{tabular}

*: Statistically significant difference.

Table (5) showed that there was a statistically significant reduction and improvement in VAP incidence rate on comparing pre and post intervention phase of the study.

\section{Discussion}

Ventilator associated pneumonia (VAP) is a critical condition and it is a leading cause of death in patients on mechanical ventilator (Perugini et al., 2015). Rate of mortality caused by VAP exceeding that of central line infections, severe sepsis and respiratory tract infections in the non-intubated patient, so education and training of nurses who are managing mechanically ventilated patients in ICU can increase their awareness about the importance of infection control and so reduce the VAP rate (Tablan et al., 2003).

This study was performed upon 
70 nurses from 5 medical and surgical ICUs at the Manial hospital, Cairo University. The current study results showed that the most defective nurses 'general knowledge about VAP was the diagnostic criteria but as regard definition, causative organisms and risk factors of VAP were improved and showed statistically significant differences after application of the educational program (Table1). This were in accordance to the results detected by Abusaad and Tantawey (2010) in their study on the effect of training program on nurses knowledge about VAP and they found improvement in their knowledge as regard definition, causes, risk factors and prevention of VAP after program implementation, but in contrary they didn't find any change in knowledge about diagnostic criteria of VAP after intervention.

The present work showed that $57.1 \%$ and $62.9 \%$ of nurses knew the correct answer about when to perform routine and aseptic hand washing during the pre-intervention assessment while only $31.4 \%$ and $38.6 \%$ respectively who gave correct answer about the contact time during alcohol rub and frequency of hand washing (Table 2). This was explained by lack of training about infection control measures.

Nurses' knowledge about hand hygiene during suctioning of ETT and oral care of mechanically ventilated patient was higher after implementation of the program and showed a statistically significant improvement of knowledge answers in the post intervention assessment (Table $2)$. These results were supported by Azab et al. (2015) who performed a cohort study in neonatal ICU and they designed a written protocol that include proper hand washing among one of the VAP bundle components.

As regard the use of PPE, about $78.6 \%$ of nurses give a correct answer about wearing a pair of gloves during suctioning and oral care which become significantly improved to $92.9 \%$ of nurses in post intervention (Table 2). They knew well the importance of wearing gloves during invasive procedures for sake of self-protection and their occupational health and safety, in addition to patient safety. But they have defective knowledge about the other types of PPE in 71.4\% which showed statistically significant improvement in post intervention assessment (87.1\%) (Table 2).

The current study showed overall 
improvement in the nurses' knowledge of VAP prevention after implementation of the educational program (Table 2). These finding were in accordance to that of Meherali and his colleagues (2011) who found that 5 hours teaching module of nurses resulted in significant improvement in their knowledge about evidenced based VAP prevention guidelines.

As regard infection control practices of invasive procedures, observational checklist in the current study showed that ICU nurses who applied aseptic hand wash before and after invasive procedures were $74.3 \%$ and $21.4 \%$ respectively and showed a statistically significant improvement in post intervention assessment to be applied by $100 \%$ and $77.1 \%$ respectively (Table 3 ). As regard wearing of clean unsterilized gloves, there were no statistically significant differences $(>0.05)$ because compliance of this practice was high $84.3 \%$ among nurses before training as shown in (Table 3).

In the present study, ICU nurses neglected aseptic hand wash after patient contact and after invasive procedures (Table 3) which may be due to their dependence on the use of gloves for their self-protection, and their deficient knowledge about the probability of cross-contamination among patients if gloves were not properly worn. In agreement with our results that of Akyol (2007) who performed a study about reasons for non-compliance of hand hygiene among nurses in Turkey and found that $7.7 \%$ of nurses are neglected hand hygiene because they wear gloves.

In the present study, $10 \%$ of ICU nurses wore aprons and 38.6\% wore facial masks during invasive procedures at the pre intervention stage which showed a statistically significant improvement in post intervention assessment to be applied by $41.4 \%$ and $81.4 \%$ respectively (Table 3 ). This was explained by the lack of awareness about the value of these PPE in their occupational health and safety and protection against infectious agents when come in contact with body fluids, in addition to lack of available resources, supplies and insufficient budget. These were consistent with that of Azzab et al (2017) who applied an intervention study in ICUs, Zagazig University hospitals and reported significant improvement and change in practice of using personal protective equipment among nurses and doctors after applying training program . 
As regard the use of chlorhexidine swab in oral care, there were non statistically significant differences in this practice between pre and post intervention (Table 4).

(Results are not tabulated) .Compliance with these practices was very high before training intervention in $87.1 \%$ compared to $92.9 \%$ of nurses after training. These results were consistent with that of Ismail and Zahran (2015) who reported that use of chlorhexidine swab was done by about $63 \%$ of nurses which become improved to $96 \%$ after training and the difference was statistically significant.

Observation of nurses' practice for adherence to the guidelines showed defective practice of brushing of teeth (Table 4), only (32.9\%) of nurses performed brushing of teeth. This is explained by lack of knowledge about VAP prevention care bundle. This practice showed a statistically significant improvement in the post intervention assessment (64.3\%). This was coping with a study done by Ross and Crumpler (2007) who measured the impact of an evidence-based practice education program on the role of oral care in the prevention of VAP and detected that improved quality of oral care provided by nurses resulted in $50 \%$ reduction of VAP rate.

Frequent endotracheal suction and using a sterile catheter that nurses practice was enhanced after program implementation to be $(80 \%)$ and $(92.9 \%)$ respectively compared to $(45.7 \%)$ and (77.1\%) before intervention (Table 4). These were in accordance to Chau et al (2007) who found improvement in the technique of ET suctioning to be $91 \%$ after training. Also was in harmony with the results reported by Kelleher and Andrews (2008) that showed higher level of compliance with the use of sterile catheter during ETT suctioning after training.

Drainage of the subglottic secretion practice showed a statistically significant improvement (Table 4). This was consistent with that of Jam Gatell et al. (2012) who reported increased obedience of nurses to guidelines practices of subglottic secretion suctioning by ( $88.6 \%)$.

About $57.1 \%$ of nurses didn't use ETT with extra lumen for subglottic drainage before training, but there was a statistically significant improvement of this practice in the post intervention assessment $(75.7 \%)$ as shown in Table (4). These were consistent with that 
found by Abusaad and Tantawey (2010) who found that using ETT with extra lumen for drainage of subglottic secretion was $2 \%$ before compared to $49 \%$ after program implementation.

Patient position may influence reflux and aspiration of infected gastric contents and thus increase the incidence of VAP. So, in the current study nurses were trained to keep mechanically ventilated (MV) patients in semirecumbent position at 30-45degree to reduce incidence of VAP occurrence and there was a statistically significant improvement of nurses' practice before (53\%) and after training (95\%) as shown in Table (4). This was in accordance to that of Bloos et al (2009) who studied the effect of training on the care of MV patients, and they found that semirecumbent position was achieved in $(24.9 \%)$ of patient before and in (46.9\%) after training.

But these results were in contrary to that of Brierly et al (2012) who recommended lowering head of bed elevation to 20-30 degrees instead of 30-to 45 degrees and they found that these are equally effective in prevention of VAP.

About $57 \%$ of nurses didn't checked gastric residual volume (GRV) before nasogastric tube feeding and didn't follow guidelines for enteral feeding due to lack of awareness of its importance in prevention of gastric aspiration. This result showed a statistically significant improvement after training (Table 4). This was in accordance to that of Mentec et al (2001) who found that the majority of ICU didn't check the GRV before every enteral feeding.

Most of nurses (62.9\%) didn't maintain ETT cuff pressure between 20-30 $\mathrm{cm} \mathrm{H}_{2} \mathrm{O}$ (Table 4) and they didn't know the normal values of cuff pressure in $(51.4 \%)$ (Table 2).But after the training program $82.9 \%$ of them became competent to use cuff meter. This was in agreement with the results of Kapucu and Özden (2017) who applied a study on nurses working at many adult ICUs at Ankara and found that (74.5\%) didn't apply cuff pressure measurement.

The current work showed that $60 \%$ of nurses avoid unnecessary circuit changes which showed significant improvement (91.4\%) after training in (Table4). This was consistent with that of Kapucu and Özden (2017) who found that about half of nurses changed the circuit only when visibly unclean.

As regard nurses' practice of 
maintain closed circuit system and avoid of unnecessary change of filter, the compliance before training were (51.4 and $78.6 \%$ respectively) compared to (87.1\% and $94.3 \%$ respectively) after training (Table 4).

These results were higher than that of Abusaad and Tantawey (2010) who observed low scores of both of use of closed circuit system and infrequent change of filter $(7.8 \%$ and $17.6 \%$ respectively) before training to be (76.5\% and $92.2 \%$ respectively).

As regards VAP incidence rate pre and post intervention; in the 2 months pre intervention total VAP episodes were $22.4 / 1000$ days and mean of $24.86 \pm$ 5.19 which reduced to be $9 / 1000$ days and mean of $5.4 \pm 7.96$ in the 2 months of post intervention, and this reduction was statistically significant (Table $5)$. These were concomitant to that of Esteban et al (2013) who conducted an interventional cohort study in Spain to evaluate the effectiveness of interventional training about care bundle of VAP rate and they found that VAP rate decreased from 28.3 to 9.1 per 1000 ventilator days after 12 months.

VAP rate was less than that of Abo Elseoud et al (2016) who applied an interventional study in a surgical
ICU at Zagazig University hospitals, they found that VAP rate dropped from $29.5 / 1000$ ventilator days to $21.5 /$ 1000 ventilator days after 6 months of intervention. These differences may be attributed to the different duration of the study and different number of patients.

\section{Conclusion and recommendations:}

From the finding of the current study, it was concluded that there was an overall improvement of nurses' knowledge and practices of evidence based guidelines for VAP prevention associated with reduction of VAP incidence rate after the implementation of educational and training program. So it is recommended to maintain continuous education and training of nurses and all health care providers about infection control measures and standard precautions, strict supervision of nurses' practices, surveillance and auditing of the VAP rate. Hospital policy should include strategies and guidelines for VAP prevention.

\section{Conflicts of interest}

None.

\section{Funding}

None. 


\section{Acknowledgment}

\section{The authors would like to acknowledge all nurses participated in the study for their cooperation and help.}

\section{References}

1. Abo Elseoud AR, AboSerea MM, Abed El Razek GM and Hussein SA (2016): An interventional study for reducing Ventilator Associated Pneumonia in Surgical Intensive Care Unit, Zagazig University Hospitals. Int $\mathbf{J}$ Curr Microbiol App Sci; 5(2): 202-14.

2. Abusaad FE and Tantawey N (2010): Nurses Knowledge and Practice to Evidence-based Guidelines for the Prevention of Ventilator Associated Pneumonia in Pediatric Intensive Care Units. Bull High Inst Public Health; 40:1.

3. Akyol AD (2007): Hand Hygiene Among Nurses in Turkey: Opinions and Practices. J Clin Nurs; 16: 431-7.

4. Augustyn B (2007): Ventilator-Associated Pneumonia Risk Factors and Prevention. Crit Care Nurs; 27(4): 32-9.

5. Azab SF, Sherbiny HS, Saleh SH, Elsaeed WF, Elshafiey MM et al (2015): Reducing ventilatorassociated pneumonia in neonatal intensive care unit using "VAP prevention Bundle": a cohort study. BMC Infect Dis; 6; 15(1):314.

6. Azzab MM, El-Sokkary RH, Tawfeek MM and Gebrie MG (2017): Prevention of Ventilator Associated Pneumonia in an Emergency Intensive Care Unit: An Intervention Study. Egypt J Med Microbiol; 26 (1) 83-94.

7. Barbier F, Andremont $\mathrm{A}$ and Wolff $\mathrm{M}$ (2013): Hospital-acquired pneumonia and ventilator-associated pneumonia: recent advances in epidemiology and management. Curr Opin Pulm Med; 19(3):21628.

8. Bloos F, Müller S, Harz A, Gugel M, Geil D et al., (2009): Effects of staff training on the care of mechanically ventilated patients: a prospective cohort study. Br J Anaesth; 103(2): 232-7.

9. Brierly J, Highe L and Hines S (2012): Reducing VAP by instituting a care bundle using improvement methodology in a UK Pediatric Intensive Care Unit. Eur J Pediatr; 171: 323-30.

10. CDC (Center for Disease Control and Prevention) (2012): Ventilator associated pneumonia (VAP) event. Device Assoc Events.6:16:13.Available at http://www.cdc. gov/nhsn/pdfs/pscmanu al/6pscvapcurrent.pdf. Accessed February 27, 2013.

11. CDC (Center for Disease Control and Prevention) (2016): Pneumonia (Ventilatorassociated [VAP] and non-ventilator-associated Pneumonia [PNEU]) Event, CDC. http:// www.cdc.gov/nhsn/PDFs/pscManual/4PSC_ CLABScurrent.pdf Accessed 15 December 2015.

12. Chan YH (2003): Biostatistics102: Quantitative Data - Parametric \& Non-parametric Tests. Singapore Med J; 44(8): 391-6.

13. Chau J, Thompson D, Chung L, Wai-Lin AU, Tam S et al., (2007): An evaluation of the implementation of a best practice guideline on tracheal suctioning in intensive care units. Int $\mathbf{J}$ Evid Based Healthc; 5(3): 354-9.

14. Esteban E, Ferrer R, Urrea M, Suarez D, Rozas L et al., (2013): The impact of a quality improvement intervention to reduce nosocomial infections in a PICU. Pediatr Crit Care Med; 14(5): 525-32.

15. Ferreira CR, de Souza DF, Cunha TM, Tavares M, Reis SS et al (2016): The effectiveness of a bundle in the prevention of ventilator-associated pneumonia. Braz J Infect Dis; 20(3):267-71.

16. Hellyer TP, Ewan V, Wilson P and Simpson AJ (2016): The Intensive Care Society recommended bundle of interventions for the prevention of ventilator-associated pneumonia. J Intensive Care Soc; 17(3):238-43.

17. Ismail $\mathrm{R}$ and Zahran E (2015): The effect 
of nurses training on ventilator-associated pneumonia (VAP) prevention bundle on VAP incidence rate at a critical care unit. J Nurs Educ; 5 (12): 42-84.

18. Jam Gatell MR, Santé Roig M, Hernández Vian Ó, Carrillo Santín E, Turégano Duaso C et al., (2012): Assessment of a training program for the prevention of ventilator-associated pneumonia. Nurs Crit Care; 17:285-92.

19. Kapucu S and Özden G (2017): Nursing Interventions to Prevent Ventilator Associated Pneumonia in ICUs. Konuralp Tip Dergisi; 9(1):35-40.

20. Kelleher S and Andrews T (2008): An observational study on the open system endotracheal suctioning practices of critical care nurses. J Clin Nurs; 17: 360-9.

21. Lin HL, Lai CC and Yang LY (2014): Critical care nurses' knowledge of measures to prevent ventilator-associated pneumonia. Am J Infect Control; 42(8):923-5.

22. Meherali S, Parpio $\mathrm{Y}$, Ali $\mathrm{T}$ and Javed, F. (2011): Nurses' knowledge of evidence based guideline for prevention of VentilatorAssociated Pneumonia in critical care areas: a pre and post-test design. Ayub Med Coll Abbottabad J; 23(1):145-9.

23. Mentec H, Dupont H, Bocchetti M, Cani $\mathrm{P}$, Ponche $\mathrm{F}$ et al.(2001). Upper digestive intolerance during enteral nutrition in critically ill patients: frequency, risk factors, and complications. Crit Care Med; 29(10):1955-61.

24. Myrianthefs PM, Kalafati M, Samara I and Baltopoulos GJ (2004): Nosocomial Pneumonia. Crit Care Nurs Q; 27(3): 241-57.
25. Osti C, Wosti D, Pandey B and Zhao Q (2017): Ventilator-Associated Pneumonia and Role of Nurses in Its Prevention. Nepal Med Assoc; 56(208):461-8.

26. Perugini M, Perugini V, Figueira F, Fontana L, Diniz J et al (2015): Impact of the ventilator bundle on ventilator-associated pneumonia (VAP) rates in a pediatric intensive care unit in Londrina-PR. Ciências Biológicas e da Saúde; 36(1): 259-66.

27. Rosenthal VD, Maki DG and Salomao R (2006): Device-Associated Nosocomial Infections in 55 Intensive Care Units of 8Developing Countries. Ann Intern Med; 145(8): 582-91.

28. Ross A and Crumpler J (2007): The impact of an evidence-based practice education program on the role of oral care in the prevention of ventilator-associated pneumonia. Intensive Crit Care Nurs; 23(3):132-6.

29. Seliman AM, El-Soussi AH, Sultan MA and Othman SY (2011): Effect of Implementing Nursing Guidelines for Tube Feeding on the Occurrence of Aspiration among Critically Ill Patients. Nat Sci; 9(11): 164-75.

30. Tablan OC, Anderson LJ and Besser R (2003): Guidelines for preventing health-care-associated pneumonia. Recommendations of CDC and the healthcare infection control practices Advisory Committee. MMWR Recomm Rep; 53(RR31):1-36.

31. WHO (World Health Organization) (2009): WHO guidelines on hand hygiene in health care: a Summary. First global patient safety challenge clean care is safer care. Geneva: 1 Accessed at 14 / 12/ 2012. 